\title{
Empirical Analysis of the E-business Enterprise Knowledge Transfer and Innovation Performance based on Multi-Agent Simulation Model
}

\author{
Hui Wang \\ School of Economic \& Management, Northwest University, Xi'an 710127, \\ Shaanxi, China \\ *wh860226@126.com
}

\begin{abstract}
In recent years, with the rapid development of E-business and network economy, technological innovation has become the driving force for the survival and development of enterprises. In this paper, the author analyzes complex adaptive system as multi -agent integrated modeling and simulation method, using simulation platform to create a virtual enterprise knowledge transfer asymmetric evolutionary game simulation model, and then make analysis of asymmetric cooperation and competition game evolution of knowledge transfer behavior. At the same time, we construct the structural equation and carries on the empirical analysis, the result shows that employee knowledge sharing self-efficacy has an indirect positive effect on innovation activity, and the indirect coefficient is 0.283; employee knowledge sharing willingness has positive effect on market performance, and the direct coefficient is 0.012. According to the results of path analysis of structural model, it can be known that innovation activity has a mediating effect, and indirect effect is produced through innovation activity. Therefore, the process of knowledge sharing and learning is an important way for enterprises to improve technological capability.
\end{abstract}

Keywords: E-business; multi-Agent modeling; knowledge transfer; innovation performance; knowledge-based enterprise

\section{Introduction}

With the development of knowledge economy and the arrival of the era of economic science and technology globalization, innovation has become an inexhaustible source of national, social and enterprise's survival and development. Rely on independent innovation driven scientific and technological progress, and lead the comprehensive and sustainable development of national economy, society and innovation oriented enterprises. In recent years, our country enterprise technology innovation has made great progress, but there are still some problems cannot be ignored [1-2]. First, long-term since the majority of enterprises to technology innovation lack of attention, investment in technological innovation is low, weak ability of innovation of enterprises, innovation level and level lower; second, the enterprise value appraisal research lags behind, limiting the technology innovation of enterprise value growth play a role; the third is new highlights the problem, have most of the enterprises ignore the non-technology factors of corporate culture, system, human resources management of technological innovation collaboration and restriction, isolated catch technology innovation, lead to poor performance of technical innovation projects[3]. Knowledge is the source of innovation, from the perspective of ontology, knowledge owners have innovative efficiency, but only through knowledge creation and sharing will, to promote innovation activities [4]. So improve staff learning and innovation of enterprise knowledge level, stimulate the enterprise innovation ability, and continue to carry out innovation activities, enhance 
innovation performance in a considerable degree of dependence on staff knowledge creation and knowledge sharing.

This study in view of the problems facing the current Chinese enterprises in technological innovation and to have the innovation ability of knowledge intensive enterprises as the research object, from the perspective of human resources of and research staff knowledge sharing the factors of technological innovation of enterprise innovation outputs effects [5]. From the perspective of total innovation management, the enterprise value appraised by the index of innovation performance; from a practical point of view, the results of the study on the one hand, for our country the practical problems facing the knowledge intensive enterprise technology innovation provides the solution and method [6-7]. On the other hand for different types of enterprises in China to carry out innovation activities provide for reference path choice of to our country enterprise in the fierce competition in the market environment to pursue continuous progress and sustainable development has important practical significance [8]. In addition, found by reading a lot of domestic related literature, experts and scholars research corporate performance in the area mainly from two angles of, one is macro level of enterprise performance, at the micro level of financial performance, employee job performance and manufacturing performance, the study abandon from the macro view of the level of enterprise performance, instead from the micro level research belongs to the innovation performance of enterprise performance, make the research in micro field has been further expanded.

\section{Multi-agent Modeling and Simulation Analysis}

\subsection{Virtual Enterprise Game}

In the virtual enterprise, the knowledge transfer behavior among the members of the organization is the key factor to realize the competitive advantage. Due to the dynamic organization characteristics of virtual enterprise, consisting of stakeholders is with the time limits of mutual benefit organization, often at the end of the cooperation, belonging to the same type of leaguer enterprises will soon become the future potential competitors. With bounded rationality in certain statistical analysis ability and on different strategic income after judgment, poor yields in will eventually found the difference, and began to learn to imitate another type of participants, so in the proportion of type changing with time is a function of time and type proportion with time change rate is determined in the speed of imitation [9]. At the same time, in the virtual enterprise knowledge transfer behavior is not only determined by the external factors of economy and environment, and in a great extent by the influence of leaguer enterprises their decision-making behavior. So it can be used to simulate the dynamic mechanism of biological evolution. In this equilibrium, any individual is no longer willing to unilaterally change its strategy, which is called Stable Strategy Evolutionary (ESS). Therefore, using the method of evolutionary game to analyze the knowledge transfer activities of virtual enterprise is more close to the reality, but also more practical significance.

Hypothesis of the two sides of the game in a class is strength strong, on a larger scale, with strong knowledge transfer and learning ability of leaguer enterprises; another kind is the scale, the strength of the smaller, but with advantage of knowledge resources for small businesses. In the transfer of knowledge, both strategies are two: one is "transfer", another is "transfer", to maintain the level of the original knowledge (Technology), learning to accept other alliance enterprises transfer of knowledge, to imitate. Due to the big leaguer enterprises occupy the market share or compete for resources larger, and therefore big leaguer enterprises were stronger capacity of innovation and knowledge transfer, the knowledge transfer and learning ability enables large enterprises to digest the knowledge transfer cost, knowledge transfer risk, more easy to integrate other alliance enterprises 
transfer of knowledge, so it is assumed that the greater strength of leaguer enterprise knowledge transfer will than strength smaller leaguer enterprises. On this basis, the two sides can be set to the payment matrix as shown in figure 1 .

Small businesses leaguer

\section{Large member companies}

\begin{tabular}{|c|c|c|}
\hline & transfer & Don't transfer \\
\hline transfer & $\mathrm{V} 1, \mathrm{~V} 2$ & $\mathrm{~V} 3, \mathrm{~V} 4$ \\
\hline Don't transfer & $\mathrm{V} \mathrm{5,} \mathrm{V} \mathrm{6}$ & 0,0 \\
\hline
\end{tabular}

\section{Figure 1. Payment Matrix Game Knowledge Transfer}

In order to simplify the description of the problem, we assume that the value of the payoff matrix, which represents the benefits of virtual enterprise knowledge transfer, in which V1, V2, V3, V4, V5 are greater than 0 . When both sides adopt knowledge transfer strategies, the size of every member enterprise income respectively is V1 and V2, V1 and >V2; when only one member enterprises adopt knowledge transfer strategy, if the big leaguer selection of knowledge transfer strategy gains for V3, a small member enterprises to follow the strategy of benefit is $\mathrm{V} 4$, if the small partners enterprise knowledge transfer, small business revenue for V6, V6 for small partners to take individual knowledge transfer strategy benefits, according to the small member enterprises on knowledge transfer risk control ability, V6 may be equal to or greater than 0 or less than or equal to 0 ; large enterprises choose to follow the strategy due to V5, the strength of enterprises, due to the small partners the relatively small size, in the game with the big leaguer, V4> V2; if both sides choose not to transfer, both parties benefit of knowledge transfer is 0 . Under the limited rationality, assuming that in the virtual enterprise large-scale leaguer enterprises take the probability of knowledge transfer for $\mathrm{x} \in[0,1]$ little leaguer enterprises by the probability of knowledge transfer to $y \in[0,1]$, replicated dynamic equation of big leaguer enterprises for

$$
\begin{aligned}
F(x) & =\frac{d x}{d t}=\left(x_{11}-\overline{u_{1}}\right)=x(1-x)\left(u_{11}-u_{12}\right) \\
& =x(1-x)\left[y\left(v_{1}-v_{3}-v_{5}\right)+v_{3}\right]
\end{aligned}
$$

The replication dynamic equation for small partners:

$$
\begin{aligned}
G(x) & =\frac{d y}{d t}=\left(y_{21}-\overline{u_{2}}\right)=y(1-y)\left(u_{21}-u_{22}\right) \\
& =y(1-y)\left[x\left(v_{2}-v_{4}-v_{6}\right)+v_{6}\right]
\end{aligned}
$$

For the big leaguer, When $\mathrm{V}_{5}>\mathrm{V}_{1}$, If $=\mathrm{v}_{3} / \mathrm{y}\left(\mathrm{v}_{3}+\mathrm{v}_{5}-\mathrm{v}_{1}\right)$, The $\mathrm{F}(\mathrm{x})$ is always 0 , which means that any $x$ value is stable state; When $y>v_{3} /\left(v_{3}+v_{5}-v_{1}\right), X *_{1}=0$ is an evolutionary stable strategy; When $\mathrm{y}<\mathrm{v}_{3} /\left(\mathrm{v}_{3}+\mathrm{v}_{5}-\mathrm{v}_{1}\right), \mathrm{X}_{2}{ }_{2}=1$ is an evolutionary stable strategy; When $\mathrm{V}_{5}<\mathrm{V}_{1}$, the value of any $\mathrm{y}$, $\left[\mathrm{y}\left(\mathrm{v}_{1}-\mathrm{v}_{3}-\mathrm{v}_{5}\right)+\mathrm{v}_{3}\right.$ ] is always greater than 0 , Is $\mathrm{X} *_{1}=0$ and $\mathrm{X} *_{2}$ $=1$ for steady state, And $\left.\mathrm{F}^{\prime}\left(\mathrm{X}^{*}{ }_{1}\right)>0, \mathrm{~F}^{\prime}\left(\mathrm{X}^{*}\right)_{2}\right)<0$, Get $\mathrm{X}^{*}{ }_{2}=1$ is an evolutionary stable state.

For small partners, When $\mathrm{V}_{6}>0$, If $\mathrm{x}=\mathrm{v}_{6} /\left(\mathrm{v}_{6}+\mathrm{v}_{4}-\mathrm{v}_{2}\right)$, then $\mathrm{G}(\mathrm{x})$ is always 0 , it means that any $\mathrm{y}$ value is stable; When $\mathrm{x}>\mathrm{v}_{6} /\left(\mathrm{v}_{6}+\mathrm{v}_{4}-\mathrm{v}_{2}\right), \mathrm{Y}^{*}{ }_{1}=0$ is an evolutionary stable strategy; When $\mathrm{x}<\mathrm{v}_{6} /\left(\mathrm{v}_{6}+\mathrm{v}_{4}-\mathrm{v}_{2}\right), \mathrm{Y}^{*}{ }_{2}=1$ is an evolutionary stable strategy; When $\mathrm{v}_{6}<0$, the value of any $\mathrm{x},\left[\mathrm{x}\left(\mathrm{v}_{2}-\mathrm{v}_{4}+\mathrm{v}_{6}\right)+\mathrm{v}_{6}\right]$ is always less than 0 , Is $\mathrm{Y}_{1}{ }_{1}=0$ and $\mathrm{Y}_{2}=1$ for steady state, and $\mathrm{G}^{\prime}\left(\mathrm{y} *_{1}\right)<0, \mathrm{G}^{\prime}\left(\mathrm{y} *_{2}\right)>0$, get $\mathrm{y}^{*}{ }_{1}=0$ is an evolutionary stable state. 


\subsection{Multi-Agent Modeling}

Agent is a computer hardware or software system and its composition between elements and between it and the environment, where there is a certain relationship between the continuous constantly changes in the perception of the outside world and their own state changes, and independent of the corresponding action. Agent based modeling is the basic unit of Agent as the system, and has a certain intelligence, and then set the specific interaction between the Agent, so as to get the model of the corresponding system. Agent based modeling method is a kind of from the bottom to the modeling method, agent system as a basic abstraction of the unit, to establish a system consisting of individual agent model. Then the suitable structure of the multi-agent system MAS (multi agent system) to assemble the individual agent, and finally establish the system model. Netlogo is a software platform designed for the analysis of complex systems, which is based on Agent. The basic architecture of the software platform is the concurrent Agent set.

The modeling method based on agent, the definition of non-symmetry of the two types of leaguer enterprises in virtual enterprise, were abstracted into two types of agent and Agents2 Agents1, them according to their properties and the external environment, according to a particular rule of conduct for knowledge transfer decision. In repeated game in the process of learning, imitation, continue to adjust the strategy game, improve the game income and finally reach the evolutionary stable state. Each type of Agent in the game when the behavior of the strategy set for $S=\{s 1 s 2\}$, that is, $S 1$ (transfer), S2 (no transfer) two pure strategy. The income of the two kind of Agent in the model is based on the $2 \times 2$ asymmetric game payoff matrix shown in Figure 1. Each agent is limited rational, have certain cognitive ability and learning ability, is not strictly in accordance with the utility maximization decision, in most cases is through the understanding of the previous game history, learning by imitation, a dynamic adjustment strategy and agent in the interaction of continuous learning and the accumulation of experience, the process is realized through the agent's learning algorithm. In this model, the two kinds of Agent after each game, according to their own choice of strategy, the opponent's strategy and the game proceeds to revise their strategy, determine the next game will take the game strategy. The game learning algorithm for all kinds of Agent is described as:

$S_{i, t+1}=\left(S_{i, t}, S_{j, t}, E_{i, t}\right)$

Let $E_{i}(t), S_{i}(t)$ respectively for each type of I Agent in the $t$ time of income and strategy, $\mathrm{S}_{\mathrm{i}}(\mathrm{t})=\mathrm{s}_{1}$ or $\mathrm{S}_{\mathrm{i}}(\mathrm{t})=\mathrm{s}_{2}$; Agent using the "transfer" and "no transfer" strategy of the fitness function:

$W_{1 s 1}(t)=y_{t} V_{1}+\left(1-y_{t}\right) V_{3}$

$W_{1 s 2}(t)=y_{t} V_{5}$

$W_{2 s 1}(t)=x_{t} V_{2}+\left(1-x_{t}\right) V_{6}$

$W_{2 s 2}(t)=x_{t} V_{4}$

Each agent is limited rational, have certain cognitive ability and learning ability, is not strictly in accordance with the utility maximization decision, in most cases is through the understanding of the previous game history, learning by imitation, a dynamic adjustment strategy and agent in the interaction of continuous learning and the accumulation of experience, the process is realized through the agent's learning algorithm. In this model, the two kinds of Agent after each game, according to their own choice of strategy, the 
opponent's strategy and the game proceeds to revise their strategy, determine the next game will take the game strategy.

\section{Research Design}

\subsection{Research Method}

The methods used in this study mainly include the following:

1) Questionnaire survey method: Through literature reading at home and abroad, to obtain a more mature research variable measurement scale, the use of Likert scale, the preparation of the initial questionnaire. On knowledge intensive enterprise executives and employees of interview and questionnaire - pre survey, cuts cannot item relating to the measured variables, the modified fuzzy and ambiguous language, debugging questionnaire, to form a large-scale issuance of the final questionnaire. By using e-mail, mail and direct distribution, we get the knowledge intensive enterprise employees distributed and recycling questionnaire.

2) Theoretical analysis and empirical analysis: By reading the literature, summarized the relevant research results of experts and scholars to construct conceptual model and research, put forward research hypotheses, using structural equation path analysis effect decomposition method to test the hypothesis that knowledge intensive relationship between employees of knowledge sharing and innovation performance.

3) Quantitative analysis and qualitative analysis: Descriptive statistical analysis of the data obtained from the questionnaire survey and reliability and validity test, in order to ensure the authenticity and validity of the data. By using structural equation path analysis and effect decomposition method, the research hypothesis is tested. Using the multivariate analysis method to explain the control variables of the regulation effect, through the analysis of quantitative data and results, according to the relevant theories and research results of experts and scholars, explaining generate results that the possible reasons, and put forward management implications.

\subsection{Variable Selection}

Innovation performance is the evaluation of the efficiency and effect of enterprise innovation activities, and it is a comprehensive reflection of enterprise innovation results. In this study, the innovation performance is the enterprise to produce products as the carrier, in the production and sales of products produced in the process of a series of innovative behavior, market performance. Total innovation management innovation performance evaluation method has the two-dimensional innovation audit as the framework; the innovation evaluation is divided into the benefit audit and process audit. This research combines the Klas innovation performance measurement index with the benefit audit and process audit, taking the customer standard, the financial standard, the internal process standard, the innovation and the learning standard as the observation dimension.

The innovation activities is refers to the knowledge intensive enterprises to product innovation as the carrier, in the entire value chain operation process, to produce a series of innovative behavior, including product innovation, the application of the patent number, production process optimization, diversified sales channels. Market performance refers to the performance of knowledge intensive enterprises through product innovation, including market share, customer satisfaction, corporate profits increased by product innovation and so on. 
Employee knowledge sharing self-efficacy refers to the knowledge intensive enterprise employees think that they have the technology and ability to share the knowledge in the organization, which can overcome the difficulties in knowledge sharing. According to the analysis of the employee knowledge sharing self-cognitive efficiency influence factors, from the employee evaluation self-effective knowledge sharing power, self-knowledge about the importance of sharing, whether knowledge sharing skills, whether they have overcome the knowledge sharing process appears difficult ability dimensions measuring knowledge intensive enterprise staff knowledge sharing cognition self-efficacy. Employee knowledge sharing willingness is a knowledge intensive enterprise staff, willing to conduct explicit and tacit knowledge sharing behavior in the organization's formal and informal occasions and members.

\section{Empirical Analysis}

\subsection{Descriptive Statistics}

When the questionnaire basic information on the design, given the different nature of the business requires a different level of innovation performance; industry characteristics affect employee communication frequency; firm size increases, employee communication path becomes longer affects the efficiency of knowledge sharing; different stages of business, human resource management strategy tends to vary affect employee knowledge sharing behavior.

Table 1. Descriptive Statistical Analysis of Sample Characteristics

\begin{tabular}{|c|c|c|c|c|}
\hline category & classification & frequency & percentage & $\begin{array}{c}\text { Cumulative } \\
\text { percentage }\end{array}$ \\
\hline \multirow{4}{*}{ Job type } & Top management & 6 & 7.1 & 7.1 \\
\cline { 2 - 5 } & $\begin{array}{c}\text { Grassroots } \\
\text { managers }\end{array}$ & 17 & 20.2 & 27.3 \\
\cline { 2 - 5 } & $\begin{array}{c}\text { Technical } \\
\text { personnel }\end{array}$ & 21 & 25.0 & 52.3 \\
\cline { 2 - 5 } & $\begin{array}{c}\text { Marketing } \\
\text { personnel }\end{array}$ & 40 & 47.7 & 100.0 \\
\hline \multirow{2}{*}{ Gender } & male & 45 & 53.6 & 53.6 \\
\cline { 2 - 5 } & female & 39 & 46.4 & 100.0 \\
\hline \multirow{3}{*}{$\begin{array}{c}\text { Working } \\
\text { time }\end{array}$} & Less than 1 years & 26 & 31.0 & 31.0 \\
\cline { 2 - 5 } & $1-3$ & 29 & 34.4 & 65.4 \\
\cline { 2 - 5 } & More than 5 years & 12 & 14.3 & 79.7 \\
\hline \multirow{2}{*}{$\begin{array}{c}\text { academic } \\
\text { degree }\end{array}$} & high school & 8 & 20.3 & 100.0 \\
\cline { 2 - 5 } & undergraduate & 60 & 71.4 & 81.0 \\
\cline { 2 - 5 } & master & 16 & 19.0 & 100.0 \\
\hline
\end{tabular}

In the surveyed enterprises, corporate nature of a large proportion of private, stateowned and state holding enterprises accounted for $25 \%$ of foreign-owned enterprises accounted for $7.1 \%$, joint ventures accounted for $17.9 \%$, private sector accounted for $48.8 \%$, other $1.2 \%$; industry category, management consulting / corporate larger proportion of education and scientific research, including IT / Internet / communications / electronics enterprises accounted for $21.4 \%$, management consulting / educational research enterprises accounted for $40.5 \%$, on a fully distributed enterprise overall sample data more evenly. It can be carried out for the study to provide a more scientific basis. In 
this study, the basic characteristics of surveyed employees conducted a statistical analysis, types of work, senior managers accounted for $7.1 \%$, accounting for $20.2 \%$ level managers, technical backbone staff accounted for $25.0 \%$, the general technical staff accounted for $31.1 \%$, accounting for marketers $8.3 \%$, other $8.3 \%$; by gender, male respondents $(53.6 \%)$, female respondents accounted for $46.4 \%$; this research group of employees mainly lowerlevel managers and technical personnel category, sex ratio was essentially flat, in now the unit within 10 working hours more evenly distributed in the various stages, each stage is relatively average employee age distribution, staff qualifications mainly at the undergraduate level and above, a sample of employees to meet the basic characteristics of knowledge workers.

\subsection{Reliability and Validity Analysis}

Reliability refers to the consistency or stability of the measurement results, which is the degree of consistency of the results of the same or similar phenomena. Use SPSS17.0 to knowledge workers share self-cognitive efficiency, knowledge workers willingness to share, innovation and market performance the scale internal consistency test and reliability by using the Cronbach $\alpha$ coefficient as a measure. In this study, Cronbach $\alpha$ coefficient of each variable is between $0.775-0.812$, the overall reliability of 0.887 (as shown in Table 2), more than the acceptable level, indicating that each scale has a high reliability.

Table 2. Reliability Test

\begin{tabular}{|c|c|c|c|}
\hline Factor & number & $\begin{array}{c}\text { Reliability } \\
\text { coefficient }\end{array}$ & $\begin{array}{c}\text { Integral reliability } \\
\text { coefficient }\end{array}$ \\
\hline $\begin{array}{c}\text { Employee knowledge sharing } \\
\text { self-efficacy }\end{array}$ & 4 & 0.812 & \multirow{2}{*}{0.887} \\
\cline { 1 - 2 } $\begin{array}{c}\text { Employee knowledge sharing } \\
\text { willingness }\end{array}$ & 5 & 0.775 & \\
\hline Innovation activities & 5 & 0.810 & \\
\hline Market performance & 5 & 0.802 & \\
\hline
\end{tabular}

The validity of the general use of general academic research is content validity, criterion validity and constructs validity. Construct validity is the extent to which a measurement tool can measure the concept or characteristics of a theory. In discussing the construct validity must take into account the comprehensiveness and exclusive problem, distributive requirement is full understanding of the construction of the original theory, and the exclusive requirement is to construct the excluded will not be relevant to the theory.

Convergent validity is concerned with the problem of distribution, and discriminant validity is exclusive problem. The construct validity of the test data is generally measured by the correlation coefficient or the factor load. Confirmatory factor analysis was obtained in this study to obtain the factor load, and the validity of the measurement data. Because the measurement scale of this study is from the research results of experts and scholars at home and abroad, the scale is more mature, suitable for the use of confirmatory factor analysis to measure the validity of the data. According to the research experience, the criteria of the fitting index are shown in Table 3. 
Table 3. Fitness Fit Index

\begin{tabular}{|c|c|c|}
\hline \multicolumn{2}{|c|}{ index } & Judgment standard \\
\hline \multirow{5}{*}{ Absolute fitness index } & $X^{2}$ & $P>0.05$ \\
\hline & RMR value & $<0.05$ \\
\hline & RMSEA value & $<0.08$ \\
\hline & GFI value & $>0.9$ \\
\hline & AGFI value & $>0.9$ \\
\hline \multirow{5}{*}{$\begin{array}{l}\text { Value added fitness } \\
\text { index }\end{array}$} & NFI value & $>0.9$ \\
\hline & RFI value & $>0.9$ \\
\hline & IFI value & $>0.9$ \\
\hline & NNFI value & $>0.9$ \\
\hline & CFI value & $>0.9$ \\
\hline \multirow{6}{*}{ Reduced fitness index } & PGFT value & $>0.5$ \\
\hline & PNFI value & $>0.5$ \\
\hline & PCFI value & $>0.5$ \\
\hline & $\mathrm{CN}$ value & $>200$ \\
\hline & $\mathrm{X}^{2}$ Degree of freedom & $<2.00$ \\
\hline & AIC value & $\begin{array}{l}\text { Less than other model } \\
\text { values }\end{array}$ \\
\hline
\end{tabular}

\subsection{Structural Equation}

To investigate and verify the knowledge intensive employees of knowledge sharing and innovation performance relationship, drawing contains the knowledge workers share self-cognitive efficiency, employee's knowledge sharing intention and innovation and market performance latent variables and observed variables. Kine (1998) think that in the SEM analysis, if the sample data observed variables of the skewness coefficient greater than 3, the kurtosis coefficients are greater than 8 may deviate from the normal distribution. Numerical variables of skewness and kurtosis of the observation system in this study are in the normal range, the data passed normality test. Model degrees of freedom for 125, the overall fitness of the chi square value for 121.374, significant probability value $\mathrm{P}=0.575>0.05$ did not reach the significant level, to accept the null hypothesis, namely the knowledge intensive employees of knowledge sharing and innovation performance model with the actual survey data can be adapted, path analysis model is based on the assumption that can be supported.

Table 4. Parameter Summary

\begin{tabular}{|c|c|c|c|c|c|c|}
\hline Factor & Weights & Covariance & Variances & Means & Intercepts & Total \\
\hline Fixed & 27 & 0 & 0 & 0 & 0 & 27 \\
\hline Labeled & 19 & 7 & 23 & 0 & 0 & 49 \\
\hline Unlabeled & 0 & 16 & 0 & 0 & 0 & 16 \\
\hline Total & 46 & 23 & 23 & 0 & 0 & 92 \\
\hline
\end{tabular}

As can be seen from table 5, the "employee knowledge sharing self-efficacy(Eksse)" has an indirect positive effect on the innovation activities, and the indirect effect is 0.283. The mediating effect by employee knowledge sharing self-cognitive efficiency to Employee Knowledge Sharing Willingness(Eksw) is same to the directly affects effect by knowledge workers willingness to share of innovation activities(Ia). The mediation effect is the product of the two direct effects of Employee Knowledge Sharing Willingness as the mediating variable, as $0.283=0.573 * 0.494$. Employee Knowledge Sharing Willingness 
has a positive effect on market performance $(\mathrm{Mp})$, direct effect is 0.012 , according to the structural model and path analysis results showed that, in the 0.001 level is not significant, but the indirect effect, indirect effect is produced through the intermediary variable creative activity, indirect effect value of knowledge workers willingness to share of innovation directly influences the effect and innovation activities value, the direct effect of market performance the product, namely $0.366=0.494 * 0.741$. And innovation activities in Employee Knowledge Sharing Willingness has a positive effect on market performance has a mediating effect.

Table 5. Structural Equation Path Coefficient

\begin{tabular}{|c|c|c|c|}
\hline equation & Direct effect & Indirect effect & Total effect value \\
\hline Eksse --> Eksw & $.573^{* * *}$ & $.000^{* * *}$ & $.573^{* * *}$ \\
\hline Eksse --> Ia & $.000^{* * *}$ & $.283^{* * *}$ & $.283^{* * *}$ \\
\hline Eksse --> Mp & $.000^{* * *}$ & $.216^{* * *}$ & $.216^{* * *}$ \\
\hline Eksw --> Ia & $.494 * * *$ & $.000^{* * *}$ & $.494 * * *$ \\
\hline Eksw --> Mp & .012 & $.366^{* * *}$ & $.378^{* * *}$ \\
\hline Ia --> Mp & $.741^{* * *}$ & $.000^{* * *}$ & $.741^{* * *}$ \\
\hline
\end{tabular}

Table 6. Multi Factor Variance Analysis of Employees' Knowledge sharing Willingness

\begin{tabular}{|c|c|c|c|c|c|c|c|c|}
\hline \multicolumn{2}{|c|}{ Source } & $\begin{array}{c}\text { sum of } \\
\text { Squares }\end{array}$ & $\mathrm{df}$ & $\begin{array}{c}\text { Mean } \\
\text { Square }\end{array}$ & $\mathrm{F}$ & Sig. & $\begin{array}{c}\text { Noncent. } \\
\text { Parameter }\end{array}$ & $\begin{array}{c}\text { Observed } \\
\text { Powera }\end{array}$ \\
\hline \multicolumn{2}{|c|}{ Hypothesis } & .077 & 1 & .077 & .320 & .613 & .320 & .069 \\
\hline \multicolumn{2}{|c|}{ Error } & .675 & 2.815 & .2406 & & & & \\
\hline \multirow{2}{*}{$\mathrm{X} 1$} & Hypothesis & 34.682 & 29 & 1.196 & 1.032 & .469 & 29.923 & .593 \\
\cline { 2 - 10 } & Error & 31.793 & 27.430 & 1.159 & & & & \\
\hline \multirow{2}{*}{ X2 } & Hypothesis & 1.576 & 5 & .315 & .275 & .923 & 1.374 & .106 \\
\cline { 2 - 10 } & Error & 31.779 & 27.703 & 1.147 & & & & \\
\hline $\mathrm{X} 1 *$ & Hypothesis & 31.929 & 26 & 1.228 & 3.217 & .003 & 83.647 & .990 \\
$\mathrm{X} 2$ & Error & 8.779 & 23 & .382 & & & & \\
\hline
\end{tabular}

Then we use sharing knowledge with employees self-awareness efficacy as control variables $X_{1}$, industry category as control variables $X_{2}$, observed variables as employee knowledge sharing will, where the null hypothesis for different sectors of the employees' knowledge sharing willingness effect is zero; varying degrees employees' knowledge sharing self-perception efficacy to employee knowledge sharing will" effect is zero; sectors and self-perception efficacy employees' knowledge sharing on the willingness to knowledge employees' interaction effect is zero, the Multivariate analysis of variance shown in Table 6 . From the table, the probability $\mathrm{P}$ value of $\mathrm{F}_{\mathrm{x} 1}, \mathrm{~F}_{\mathrm{x} 2}$ and $\mathrm{F}_{\mathrm{x} 1} * \mathrm{x} 2$ respectively as $0.469,0.932,0.003$, at the 0.05 level of significance, so accept the null hypothesis can be considered different sectors, with varying degrees of employee knowledge sharing self-perception efficacy, employee knowledge sharing will overall there is no significant difference between the mean of employee knowledge sharing will effect simultaneously zero. The $\mathrm{F}_{\mathrm{x} 1 * \mathrm{x} 2}$ probability $\mathrm{P}$ values less than the significance level, it should reject the null hypothesis can be considered different industries in the Employees' Knowledge Sharing self-perception efficacy to employee knowledge sharing will generate significant interaction. Thus, different industries in the Employees' Knowledge Sharing self-perception efficacy to employee willingness to share knowledge will have a significant impact. 


\section{Conclusions}

Under the background of knowledge economy era, this research is based on the perspective of sustainable development of enterprises, and the research topic of knowledge sharing and innovation performance of knowledge intensive enterprises is determined. By reading a lot of literatures, defines the concept of knowledge intensive enterprises, knowledge sharing and innovation performance. The experts in the knowledge sharing and innovation performance, employee knowledge sharing and innovation performance relations research the comprehensive. Research methods and technical routes are designed. In study design, select the innovation and market performance as the explained variable, selects employee knowledge sharing effectiveness of self-perception and knowledge workers willingness to share as the explanatory variables, draw out the conceptual model, the paper puts forward the research hypothesis. In the part of empirical research, the survey data were descriptive statistics analysis, through reliability analysis, it is shown that the data has good reliability, through confirmatory factor analysis shows that data has good validity, using the structural equation analysis and path effect decomposition method, for knowledge intensive enterprise staff knowledge sharing mechanism of innovation performance interpretation, the use of multivariate variance analysis method, illustrates the effect of the control variables.

Employee knowledge sharing self-efficacy "has a positive impact on the employees' knowledge sharing willingness. It can be explained by Mcclelland's theory of achievement motivation and Atkinson's expected value theory. Achievement motivation contains achievement needs and affinity needs; the expected value theory emphasizes the possibility and value of the target to assess the value of action after the action. In the knowledge intensive enterprises with knowledge sharing cognition self-efficacy employees most has the achievement motivation and need for affiliation, they hope in the harmonious atmosphere of team work, through the communication of knowledge sharing is effective way to achieve this goal. Get knowledge workers willingness to share representative of innovation positive effect conclusion may be, in the knowledge intensive enterprises, employees according to their own wishes knowledge sharing, in the process of sharing, the diversity of knowledge will appear collision and even conflict, but there is no doubt that individual knowledge within the organization get optimal circulation, and the formation of the enterprise capability. Therefore, the process of knowledge sharing and learning is the process of enterprise's ability to achieve technological capability. Therefore, knowledge intensive enterprise employee knowledge sharing will be transformed into a series of innovative activities, including product innovation, process innovation, marketing, service innovation. This conclusion tells us that in the knowledge intensive enterprises, managers can by providing effective knowledge sharing platform stimulate employee knowledge sharing intention, as in corporate culture advocacy knowledge sharing concept, emphasizing establish innovative organizations, establish a shared database based on network, to carry out knowledge forum.

\section{References}

[1] E. Cabrera, and A. Cabrera, "Fostering knowledge sharing through people management practices", the International Journal of Human Resource Management, vol. 16, (2005), pp. 720-735.

[2] G. Bock and Y. Kim, "Breaking the Myths of Rewards, an Exploratory Study of Attitudes About Knowledge Sharing", Information Resource Management Journal, vol. 15, (2014), pp. 14-21.

[3] H. Berends and K. Debackere, "Knowledge Sharing Mechanism industrial Research", R\&D Management, vol. 31, (2006), pp. 85-95.

[4] L. Lu and P. Koch, "Managerial Knowledge Sharing: The Role of Individual, Interpersonal, and Organizational Factors", Management and Organization Review, vol. 2, (2014), pp. 15-41.

[5] A. Cabrera and W. Collins, "Determinants of Individual Engagement in Knowledge Sharing", International Journal of Human Resource Management, vol. 17, (2004), pp. 245-264. 
[6] N. Liu, "Human resource practices and individual knowledge-sharing behavior: an empirical study for Taiwanese R\&D professionals", The International Journal of Human Resource Management, vol. 2, (2011), pp. 981-997.

[7] R. Alwis and E. Hartmann, "The Use of Tacit Knowledge Within Innovative Companies: Knowledge Management in Innovative Enterprises", Journal of Knowledge Management, vol. 12, (2008), pp. 133147.

[8] G. Bhatt, "Management Strategies for Individual Knowledge and Organizational Knowledge", Journal of Knowledge Management, vol. 6, (2014), pp. 31-39.

[9] R. Boland and V. Tensaki, "Perspective Making and Perspective Taking in Communities of Knowing", Organization Science, vol. 6, (1995), pp. 350-372.

\section{Author}

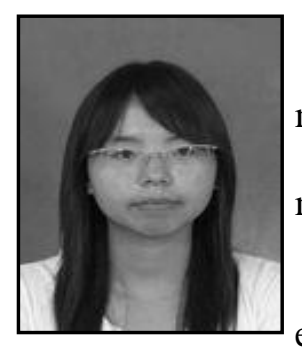

Wang Hui, 1986.2, Xi'an, Shaanxi, P.R. China

Current position, grades: the doctor of School of economic\& management, Northwest University, Shaanxi, China.

Scientific interest: Her research interest fields include knowledge management and innovation.

Publications: More than 10 papers published.

Experience: She is pursuing her doctoral degree, has teaching experience of 2 years and completed two scientific research projects. 
International Journal of $u$ - and e- Service, Science and Technology Vol.9, No. 9 (2016) 